\title{
Изменения регионарной перфузии легких у ликвидаторов последствий аварии на Чернобыльской АЭС
}

Сибирский государственный медицинский университет: 634050, Томск, Московский тракт, 2

\section{Ya.V.Porovsky, V.D.Zavadovskaya, F.F.Tetenev, L.M.Ogorodova \\ Regional pulmonary perfusion in Chernobyl clean-up workers}

\begin{abstract}
Summery
Computed tomography and lung perfusion scintigraphy were performed in 12 Chernobyl clean-up workers exposed to high air pollution during their work in Chernobyl and 15 patients with chronic obstructive lung disease (COPD). Average upper / lower lung field perfusion coefficient in Chernobyl patients was lower when compared to the COPD patients but equal density of the lungs. Abnormal blood flow redistribution from lower lung fields to upper ones could be caused to inhaled "Chernobyl dust" and subsequent development of perivascular fibrosis.

Key words: Chernobyl, COPD, lung perfusion scintigraphy, lung perfusion coefficient.
\end{abstract}

\section{Резюме}

Проведена компьютерная томография и перфузионная сцинтиграфия легких у 12 ликвидаторов последствий аварии на Чернобыльской АЭС, участвовавших в восстановительных работах, связанных с повышенной запыленностью, и 15 больных хронической обструктивной болезнью легких (ХОБЛ). Коэффициент перфузии верхних / нижних отделов легких (Upper / Lov) у ликвидаторов был в среднем ниже, чем у больных ХОБЛ при одинаковой воздушности легочной ткани. Нарушение перераспределения кровотока от нижних к верхним отделам легких при ингаляции "чернобыльской пыли" у ликвидаторов может быть связано с развитием периваскулярного фиброза.

Ключевые слова: ликвидаторы аварии на Чернобыльской АЭС, ХОБЛ, перфузионная сцинтиграфия легких, коэффициент перфузии.

Ликвидаторы аварии на Чернобыльской АЭС подверглись сочетанному воздействию как внешнего $\gamma$ - и $\beta$-излучения, так и внутреннего, возникшего в результате ингаляционного поступления радионуклидов в легкие $[1,2]$.

Достаточно большой опыт радиационной медицины свидетельствует о сложности выявления клинически значимых проявлений при поступлении радиоактивных изотопов в дозах, близких к допустимым, или в количествах, несколько их превышающих [3]. Вероятность ингалирования слаборастворимых соединений трансурановых изотопов и депонирования их в "барьерном" органе - легких - требует тщательного исследования бронхолегочной системы у ликвидаторов последствий аварии (ЛПА) на Чернобыльской АЭС [4, 5].

Благодаря высокой информативности лучевых методов исследования представляется возможным оценить состояние легких с помощью компьютерной томографии высокого разрешения (КTBР) и радионуклидной ангиографии. Их использование позволяет изучить структуру легких, косвенно оценить соответствие вентиляции и кровотока, нарушение соотношения которых является основой формирования и прогрессирования легочной патологии как при хронической обструктивной болезни легких (ХОБЛ), так и при пульмонопатии, обусловленной ингаляционным поступлением радионуклидов в составе "чернобыльской пыли", а также определить возможный вклад последних в развитие патологии легких у ЛПА на Чернобыльской АЭС.

Цель исследования - установить особенности регионарной перфузии легких у ЛПА на Чернобыль- ской АЭС путем анализа результатов КТ легких, проведенной в сочетании с перфузионной сцинтиграфией.

\section{Материалы и методы}

Проведен анализ результатов КТВР и радионуклидной ангиографии у 12 мужчин - ЛПА на Чернобыльской АЭС (1-я группа - основная) с подозрением на новообразование в легких, не подтвердившееся при обследовании. Все они с конца мая 1986 г. и в 1987 г. участвовали в строительных работах на территории Чернобыльской АЭС, захоронении зараженного грунта, дезактивации. Средний возраст ЛПА составил 49,6 \pm 1,2 года, суммарная доза внешнего $\gamma$-облучения $-14,0 \pm 1,5 \mathrm{cГр}$, длительность участия в поставарийных работах составила в среднем $3,5 \pm 1,2$ мес. Все ЛПА курили 18,75 $\pm 1,76$ сигареты / день, стаж курения $-20,1 \pm 3,1$ года.

Во 2-ю группу (сравнения) вошли 15 больных ХОБЛ (средний возраст $-51,2 \pm 1,4$ года), у которых в анамнезе не было указания на воздействие радиационного фактора. Все они курили 19,78 \pm 1,11 сигареты / день, стаж курения - 22,8 $\pm 1,9$ года. Формирование этой группы было обусловлено необходимостью выявить собственно радиационные изменения в легких в связи с высоким распространением курения среди ЛПА.

В составе 3-й группы (контрольной) были 6 пациентов того же возраста, некурящих, без радиационного облучения в анамнезе.

КТ грудной полости проводилась на 1-срезовом спиральном компьютерном томографе Toshiba Xpress 
$G X$ (Toshiba, Япония) по стандартной программе в фазе вдоха. Толщина томографического слоя составила 7,0 мм. Денситометрическая оценка плотности легочной ткани (в Ед. Х.) выполнялась на 3 уровнях: на 2 см выше дуги аорты, на уровне бифуркации трахеи, на 2 см выше уровня купола диафрагмы. 3она исследования включала легочную ткань от прикорневых до субплевральных отделов легкого, кроме корня легкого с его структурами. На тех же уровнях выполнялась серия "тонких срезов" с толщиной томографического слоя 1,0 мм и восстановлением изображения по алгоритму высокого разрешения для выявления и оценки структурных изменений легочной ткани (эмфизема легких, пневмофиброз, его характер). Оценка данных изменений проводилась визуально.

Радионуклидную ангиографию легких выполняли с 99mТс-микросферами альбумина. Количественную оценку регионарных сцинтиграмм каждого легкого проводили путем определения коэффициента Upper / Lov (U / L), отражающего соотношение paдиоактивности верхних и нижних отделов легких [6].

Среднее давление в легочной артерии (ЛАД рассчитывали по методу, предложенному лабораторией радионуклидных методов исследования НИИ кардиологии Томского НЦ СО РАМН и рекомендованному для неинвазивного определения давления в легочной артерии с помощью радионуклидной ангиопульмонографии [7].

Статистическая обработка результатов исследования проводилась с применением программ Statistica 6.0 for Windows. Рассчитывали выборочное среднее $(M)$ и стандартную ошибку выборочного среднего $(m)$. Статистическую значимость различий сравниваемых величин оценивали с помощью непараметрического критерия Манна-Уитни.

\section{Результаты и обсуждение}

В группе контроля средние значения плотности легочной ткани справа и слева в верхних, средних, нижних отделах легких колебались от $-790,2 \pm 5,9$ до $-804,6 \pm 9,1$ Ед. Х. В 2 случаях имел место перибронхиальный фиброз. Коэффициент U / L (соотношение легочного кровотока между нижними и верхними отделами легких) составил от 0,43 до 0,64 (в среднем 0,59 $\pm 0,12)$, показатели ЛАД вались от 11 до 15,5 мм рт. ст. (в среднем 13,27 \pm
2,40 мм рт. ст.) и соответствовали показателям у здоровых лиц [7].

В группе ЛПА на Чернобыльской АЭС в 5 случаях было выявлено повышение воздушности отделов легких $>-900$ Ед. Х. вследствие эмфиземы (максимально - до -954 Ед. Х.), в 3 случаях из-за пневмосклеротических изменений происходило уплотнение легких (максимально - до -750 Ед. Х.), в 7 - определялся мелкосетчатый распространенный фиброз. В 8 случаях $(66,7 \%)$ регистрировалось сочетание перибронхиального и периваскулярного фиброза, у 4 человек $(33,3$ \%) был только периваскулярный фиброз.

Во 2-й группе в 7 случаях выявлялось повышение воздушности отделов легких > -900 Ед. Х. (максимально - до -951 Ед. Х.), в 1 случае - уплотнение паренхимы легких до -778 Ед. Х. Мелкосетчатый распространенный фиброз определялся у 9 человек. Сочетание перибронхиального и периваскулярного фиброза установлено у 8 (53,3 \%) пациентов, только периваскулярный и перибронхиальный фиброз у $1(6,7 \%)$ и 6 (40 \%) больных соответственно.

Средние величины показателей плотности легочной ткани по всем отделам легких справа и слева в 1-й и 2-й группах статистически не различались, но превышали те же значения в контрольной группе (таблица).

Известно, что в различных легочных полях вторичная диффузная эмфизема может быть неравномерной, что связывают с особенностями структуры легких. Чаще всего эмфизема более выражена в верхних долях, где слабее развиты прослойки соединительной ткани и лучше коллатеральная вентиляция [8].

В настоящем исследовании у больных 2-й группы плотность легочной ткани в базальных отделах была недостоверно ниже, чем в верхних. В 5 случаях в нижних отделах она составила $<-900$ Ед. Х. при характерных для эмфиземы изменениях легочных объемов (функциональная остаточная емкость легких $127,8 \%_{\text {долж.; остаточный объем легких }-134,0 \%}$ долж.; общая емкость легких - 115,5\% долж.). По данным литературы, в части случаев это может быть связано с полиморфизмом генов GSTP1, EPHX1 и MMP1, ответственных за риск развития апикальной или базальной эмфиземы при ХОБЛ [9].

При количественной оценке коэффициента U / L в 1-й группе происходило перераспределение легочной перфузии в пользу верхних долей с колебанием

Таблица
Показатели денситометрии легочной ткани и радионуклидной ангиографии легких

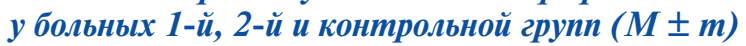

\begin{tabular}{|c|c|c|c|c|c|c|c|c|}
\hline & \multicolumn{6}{|c|}{ Показатели денситометрии, Ед. X. } & \multicolumn{2}{|c|}{ Радионуклидная ангиография } \\
\hline & \multicolumn{2}{|c|}{ Верхние отделы } & \multicolumn{2}{|c|}{ Средние отделы } & \multicolumn{2}{|c|}{ Нижние отделы } & \multirow[t]{2}{*}{ U/L } & \multirow{2}{*}{$\begin{array}{c}\text { ЛАД ср., } \\
\text { мм рт. ст. }\end{array}$} \\
\hline & Справа & Слева & Справа & Слева & Справа & Слева & & \\
\hline 1 -я группа ( $n=12)$ & $-864,8 \pm 6,7^{*}$ & $-873,7 \pm 4,4^{*}$ & $-868,2 \pm 7,8^{\star}$ & $-887,6 \pm 12,4^{*}$ & $-854,2 \pm 13,5^{*}$ & $-844,9 \pm 8,6^{*}$ & $1,13 \pm 0,08^{*, * *}$ & $30,13 \pm 2,54^{*}$ \\
\hline 2-я группа ( $n=15)$ & $-847,3 \pm 9,9^{*}$ & $-855,20 \pm 7,78^{*}$ & $-862,6 \pm 1,9^{*}$ & $-869,6 \pm 8,6^{*}$ & $-872,4 \pm 12,0$ * & $-870,6 \pm 12,0^{*}$ & $1,31 \pm 0,07^{*}$ & $28,27 \pm 1,60^{*}$ \\
\hline 3-я группа (n = 6) & $-791,4 \pm 7,6$ & $-799,2 \pm 9,5$ & $-797,2 \pm 4,6$ & $-790,1 \pm 5,9$ & $-801,3 \pm 10,2$ & $-804,6 \pm 9,1$ & $0,59 \pm 0,12$ & $13,27 \pm 1,24$ \\
\hline
\end{tabular}

Примечание: * - достоверность различия показателей с 3-й группой ( $p<0,05)$, ** - достоверность различия показателей со 2-й и 3-й группами (p<0,05). 
$\mathrm{U} / \mathrm{L}$ от 0,85 до 1,47 . При этом у 6 человек меньшая плотность легочной ткани в нижних отделах легких, по сравнению с верхними, характеризовалась преобладанием перфузии нижних отделов, т. е. не сопровождалась обеднением сосудистого русла.

Во 2-й группе перераспределение легочной перфузии в пользу верхних долей было более выраженным (U / L изменялся от 0,98 до 1,73). Средние значения коэффициента U / L у ЛПА были ниже, чем в группе больных ХОБЛ $(1,13 \pm 0,08$ и $1,31 \pm 0,07$ соответственно; $p<0,05)$. при этом повышение ЛАД ср. было несколько бо́льшим, чем в других группах (таблица).

Известно, что внутриальвеолярное давление имеет одинаковую величину на всех участках легких, поскольку альвеолы сообщаются между собой и давление в них выравнивается, а разница его гравитационной составляющей в верхних и нижних отделах легких практически равна нулю. Согласно представлению J.B.West [10] о неравномерности распределения регионарного кровотока в легких, более высокое трансмуральное давление в кровеносных сосудах основания легких способствует их пассивному растяжению и увеличению емкости. Низкое и даже отрицательное трансмуральное давление в сосудах верхних отделов легких сопровождается их коллабированием. Они почти не перфузируются, хотя и вентилируются. Воздухосодержащие альвеолы этих зон представляют собой функциональное мертвое пространство.

ХОБЛ сопровождается нарушением гемодинамики малого круга, повышением легочно-сосудистого сопротивления, формированием легочной гипертензии и легочного сердца $[11,12]$. При этом к ранним изменениям, возникающим еще до стойкого повышения общелегочного сопротивления и развития легочной гипертензии, относится перераспределение кровотока из нижних отделов легких к верхним, в связи с чем U / L начинает превышать диапазон этого показателя у здоровых лиц $(0,5-0,7)$ [6].

Полученные данные позволили установить, что у обследованных ЛПА на Чернобыльской АЭС перераспределение кровотока происходит в пользу верхних отделов легких с увеличением коэффициента $\mathrm{U} / \mathrm{L}$ до $1,13 \pm 0,08$. В то же время коэффициент $\mathrm{U} / \mathrm{L}$ у этих пациентов в среднем оставался ниже, чем у больных ХОБЛ $(1,31 \pm 0,07)$, хотя воздушность верхних и нижних отделов легких в 1-й и 2-й группах сопоставима.

Из данных литературы известно, что у ЛПА на Чернобыльской АЭС при гистологическом исследовании трансторакальных биоптатов в отдаленные сроки после участия в восстановительных работах, в отличие от больных ХОБЛ, обнаруживаются признаки легочного васкулита [13]. Типичные для ЛПА патогистологические изменения сосудов характеризуются поражением микроциркуляторного русла системы бронхиальной и легочной артерий в виде их гиалиноза или мускуляризации в сочетании с пролиферацией эндотелиоцитов. Они обусловлены как прямым повреждающим действием ингалированной пыли на эпителий дыхательных путей, так и опосредованной активацией макрофагов и системы цитокинов [14].

Выявленные нами особенности регионарного изменения коэффициента U / L у ЛПА предполагают локальное нарушение соотношения легочной вентиляции и кровотока. Как показали данные КТВР, обнаруженные изменения могут быть связаны с периваскулярным фиброзом, который приводит к менее эффективному использованию функционального мертвого пространства и является причиной дополнительного повышения давления в легочной артерии.

\section{Заключение}

1. У ЛПА на Чернобыльской АЭС выявлено достоверно меньшее перераспределение легочного кровотока в верхние отделы легких, по сравнению с больными ХОБЛ, при сопоставимой в обеих группах плотности верхних и нижних отделов легких.

2. При КТ легких у всех без исключения ЛПА на Чернобыльской АЭС установлен периваскулярный фиброз, в сравнении с 59,7 \% больных ХОБЛ, не работавших в условиях повышенного радиационного фона, что свидетельствует о вовлечении сосудистого компонента в нарушения регионарной перфузии у этой группы обследованных.

Таким образом, нарушения перераспределения кровотока от нижних к верхним отделам легких у ЛПА на Чернобыльской АЭС, выявленные в результате обследования методами КТ в сочетании с перфузионной сцинтиграфией, обусловлены развитием периваскулярного фиброза - вероятно, вследствие высокой чувствительности структурных элементов сосудистой стенки к облучению компонентами "чернобыльской пыли".

\section{Литература}

1. Ильин Л.А., Губанов В.А. (общ. ред.). Крупные радиационные аварии: последствия и защитные меры. М.: Изд-во "АТ"; 2001.

2. Чучалин А.Г. Аэрозольные радионуклидные пневмопатии. Пульмонология 1993; 4: 6-9.

3. Гуськова А.К., Байсоголов Г.Д. Лучевая болезнь человека. М.; 1971.

4. Кутьков В.А., Муравьев Ю.Б., Арефьева З.С., Камарицкая О.И. "Горячие частицы" - взгляд спустя семь лет после аварии на Чернобыльской АЭС. Пульмонология 1993; 4: 10-19.

5. Чучалин А.Г., Черняев А.Л., Вуазен К. Патология органов дыхания у ликвидаторов аварии на Чернобыльской АЭС. М.: Грантъ; 1998.

6. Карпов Р.С., Дудко В.А., Кляшев С.М. Сердце-легкие: Патогенез, клиника, функциональная диагностика и лечение сочетанных форм ишемической болезни сердца и хронических обструктивных болезней легких. Томск: STT; 2004.

7. Лишманов Ю.Б., Кривоногов Н.Г., Завадовский К.В. Радионуклидная диагностика патологии малого круга 
кровообращения. Томск: STT, 2007.

8. Есипова И.К. Легкое в патологии. Новосибирск: Изд-во "Наука", Сиб. отд-ние; 1975; ч. 1: 203.

9. DeMeo D.L., Hersh C.P., Hoffman E.A. et al. Genetic determinants of emphysema distribution in the national emphysema treatment trial. Am. J. Respir. Crit. Care Med. 2007; 176 (1): 42-48.

10. West J. B. Pulmonary pathophysiology. London; 1982.

11. Шмелев Е.И. Хроническая обструктивная болезнь легких. М.; 2003.

12. Weitzenblum E. Chronic cor pulmonale. Heart 2003; 89: 225-308.

13. Чикина С.Ю., Копылев И.Д., Черняев А.Л. и др. Особенности патологии органов дыхания у ликвидаторов аварии на Чернобыльской АЭС. Пульмонология 2006; 4: 33-38.
14. Самсонова М.В., Черняев А.Л., Копылев И.Д., Чикина С.Ю. Патологическая анатомия легких при ингаляционном поражении многокомпонентной пылью после аварии на Чернобыльской АЭС в отдаленные сроки. Пульмонология 2006; 4: 46-52.

\section{Информация об авторах}

Поровский Ярослав Витальевич - к. м. н., доцент кафедры пропедевтики внутренних болезней СибгМУ; тел.: (3822) 52-69-68; e-mail: puss@tomsk.gov.ru

Завадовская Вера Дмитриевна - д. м. н., проф., зав. кафедрой лучевой диагностики и лучевой терапии СибгМУ; тел.: (3822) 53-20-31; e-mail: radiology@ssmu.ru

Тетенев Федор Федорович - д. м. н., проф., зав. кафедрой пропедевтики внутренних болезней СибГМУ; тел.: (3822) 52-69-68

Огородова Людмила Михайловна - д. м. н., проф., член-кор. РАМН, проректор по научной работе и последипломной подготовке СибгМУ; тел.: (3822) 53-23-04; e-mail: Im-ogorodova@mail.ru

Поступила 05.05.08 (с) Коллектив авторов, 2009 УдК 616.24-092-057 